FILOZOFIA

Roč. 76, 2021, č. 6

DOI: https://doi.org/10.31577/filozofia.2021.76.6.4

\title{
ON SOCIAL CONSEQUENCES OF EPISTEMIC IGNORANCE
}

JADWIGA BŁAHUT-PRUSIK, University of Warmia and Mazury in Olsztyn, Instytut Filozofii, Olsztyn, Poland

BŁAHUT-PRUSIK, J.: On Social Consequences of Epistemic Ignorance FILOZOFIA, 76, 2021, No 6, pp. $436-450$

\begin{abstract}
There are a number of phenomena which can be analysed in relation to epistemic injustice, either as its sources, manifestations or implications. The aim of the study is to show social consequences of epistemic violence, and the related epistemic ignorance, as well as pointing out that social injustice is deeply rooted in the epistemic layer, which sanctions and justifies it, while making it invisible. Wide ramifications of relationships between these two necessitate complementing traditional epistemology with social epistemology focused on practical social effects of particular epistemological assumptions.
\end{abstract}

Keywords: Epistemology of ignorance - Social epistemology - Epistemic injustice - Imaginative geography

\section{Introduction}

Today, epistemology is becoming one of the key areas of criticism of modernity, exposing the Eurocentric bias of knowledge. As such, it is also becoming a significant tool in the fight for social justice. The latter aim is related to a growing conviction that political, economic and cultural injustice and ignorance, which is directly related to injustice, have their sources in epistemic injustice, which is their point of reference, establishment and sanctioning (Berreto 2014, 395, 397). It is, however, a reciprocal process and, at the same time, a self-powered one. It is not only that political, economic, and social injustices are rooted in epistemic injustice, but also social injustice may be the cause of epistemic injustice. Close ties between power, knowledge and ignorance are confirmed in, among others, the feminist thought, decolonial or critical race theory, which were born in response to epistemic injustice. They often offer some reflection on ethical and political knowledge practices. Such practices concern, among others, knowers who have been wronged in their capacities as knowers when their capacities are taken away from them or limited. For example: "school curricula and academic disciplines are structured in ways that systematically ignore, distort, and / or discredit particular intellectual traditions" (Pohlhaus 2017, 44). Miranda Fricker also speaks of epistemic injustice meant like that. She talks about two forms of epistemic 
injustice and theorizes them as consisting in the wrong done to someone specifically in their capacity as a knower. She calls them testimonial injustice and hermeneutical injustice. "Testimonial injustice occurs when prejudice causes a hearer to give a deflated level of credibility to a speaker's word; hermeneutical injustice occurs at a prior stage, when a gap in collective interpretive resources puts someone at an unfair disadvantage when it comes to making sense of their social experiences" (Fricker 2007, 1).

The wrongs of groups seen as inferior - as pointed out by Gaile Pohlhaus - are reinforced from the inside through epistemic practices which result predominantly from the very structures of epistemic institutions (Pohlhaus 2017, $43-71$ ). This means that a socially constructed identity has real epistemic consequences for the way people perceive the world and the way they function in it. That is why, according to Boaventura de Sousa Santos, achieving global justice is impossible without establishing epistemic justice at the same time (Santos, 2014). The aim of this study is to show social implications of epistemic violence and the related epistemic ignorance. Recognizing broad consequences of relationships between these two makes it necessary to complement traditional epistemology with social epistemology focused on practical social effects of particular epistemological assumptions.

\section{On the need of research into the epistemology of ignorance}

The complex phenomenon of ignorance is considered in the field of new kind of postulated epistemology, which is called the epistemology of ignorance (lack of knowledge). It aims at identifying various forms of ignorance, analysing ways they are established and maintained, as well as recognising the role they play in practices of knowledge. Like the epistemology of the South, ${ }^{1}$ the new kind of epistemology turns towards a social perspective, looking for connections between knowledge, power, politics and ignorance, at the same time focusing on their close relationship. In this context, Charles W. Mills postulates complementing traditional epistemology, based on mental operations, with social epistemology, focused on social pathways of reaching knowledge and investigating its practical consequences. While classical epistemology strives at eliminating false beliefs, social epistemology emphasizes supra-personal relationships and their effect on the individual. Its aim is to understand how certain social structures facilitate promoting flawed processes, how to leave them behind, or how to contribute to weakening them in a broader cognitive context (Mills 2007, 17,

\footnotetext{
${ }^{1}$ Santos constructs the epistemology of the South in response to the experience of epistemic violence. It is a project that embeds epistemology in the experiences of the Global South. It is a reflection critical of the Western narrative, protesting against epistemic violence, ideological poverty, and the material effects of neoliberal globalization. The new epistemic optics aims to undertake radically decolonial critique of socially entrenched dichotomies, going beyond the Eurocentric utopian nightmares exported as global imperial projects for the rest of the world.
} 
23). Social epistemology, with its postulate of complementing traditional functions of epistemology, based on Cartesian methodology, to a certain extent becomes its antithesis. It negates the possibility of establishing a universal epistemological methodology that proposes a demand of epistemically rejecting everything that is beyond the limits of sense which it outlines. Proffering the postulate of restoring the epistemic meaning to the subjects of knowledge which was erased and marginalized, social epistemology not only explains the reality, but also becomes a tool in the fight for social justice. As such, it focuses also on the issue of epistemic violence - one of the main manifestations of ignorance. Noticing a relation between epistemic violence and epistemic ignorance is crucial for at least several reasons strictly connected with global justice which is postulated by Santos. It is a reflection necessary in the process of re-establishing the subjectivity of their voice / significance to subaltern groups. It is a reflection important for affirmative actions aimed at levelling educational and vocational chances of social minorities that have been discriminated against. It is also an indispensable consideration when attempting to identify and overcome contemporary threats. Finally, it is a possibility to view some present deep divisions from a perspective different to the Western one.

Gayatri Chakravorty Spivak defines epistemic violence as the way to silence subaltern classes. That results in a decline of tribal, provincial knowledge, the one that does not fit into Western epistemic practices. The essence of epistemic violence is encapsulated aptly by Kristie Dotson: in its general meaning, epistemic violence is an intentional or unintentional refusal of a linguistic exchange between subjects and their audiences in a communicative and reciprocal way. What makes such a refusal harmful is pernicious ignorance. The ignorance does harm due to the fact that it entails a harmful practice of silencing. (Dotson 2011, 238 - 239). "Epistemic violence, then, is enacted in a failed linguistic exchange where a speaker fails to communicatively reciprocate owing to pernicious ignorance" (Dotson 2011, 239). The aim of the epistemology of ignorance is to expose and analyse relationships between social injustice and what is believed to be knowledge (an epistemological norm), between who validates the norm within cognition and how this process impacts gaining the privileged epistemic, thus also social, position of the norm-giver. Epistemic violence is one of the key elements in every process of domination. As indicated by Enrique Galván-Álvarez, epistemic frameworks legitimize and guarantee the practices of economic, political and cultural domination, abuse and control (Galván-Álvarez 2010, 12). Without the epistemic foundation, they would lose the constitutive source of their validity. Epistemic violence leads in a straightline to epistemic injustice. They both refer to the issue of knowledge and participation in communicative practices. The consequences of silencing include: 
Wrongful treatment and unjust structures in meaning-making and knowledge producing practices, such as the following: exclusion and silencing; invisibility and inaudibility (or distorted presence or representation); having one's meanings or contributions systematically distorted, misheard, or misrepresented; having diminished status or standing in communicative practices; unfair differentials in authority and/or epistemic agency; being unfairly distrusted; receiving no or minimal uptake; being co-opted or instrumentalized; being marginalized as a result of dysfunctional dynamics; etc. (Kidd, Medina, Pohlhaus 2017, 24)

Epistemic violence is directly related to epistemic ignorance. According to Linda Martín Alcoff, the way to fight against both of these phenomena is to, among others, study a range of practices which shape our convictions, and which are epistemically seemingly unreliable but are socially functional. Although epistemological ignorance is not a novel topic in mainstream epistemology, it seems novel to recognise it not as an effect of neglected epistemic practice, but a significant epistemic practice in itself. The epistemology of ignorance strives at explaining and confirming the fact that the practices of ignorance - such as socially accepted intentional ignorance, although mistakenly justified - have a structural character. Identities, socially located forms of beliefs are determined by various types of structural social conditions, which in some cases are epistemically flawed, inadequate to reality. This is where social epistemology visibly intersects with social and political theory (Alcoff 2007, 39-43).

Alcoff argues that further research in the field of epistemology of ignorance is necessary. This need, in her view, results from at least three basic reasons. The first one, quoted after Lorraine Code, binds ignorance with the general fact of the location of the knowing subject. Diverse social locations generate different structures of reality and provide different perspectives on it. The location, identity of subject and sociopolitical structures in which they are set, place them somewhere - they are limited and activated by the specificity of their location; thus, they are never unbiased. Constantly exposed to ignorance of other subjects, also strongly rooted in their different "somewhere," the knowing subject themselves remains irreversibly inclined toward ignorance (Alcoff 2007, 40 - 43). The condition which guarantees avoiding epistemic ignorance, as well as its social consequences, is to embrace an assumption that knowledge is fragmentary and incomplete, and that there are boundaries, limitations of what a particular kind of knowledge allows one to know about a given human experience. Santos calls it an epistemological difference or asymmetry, stating that "[b]oundaries and possibilities of every knowledge ultimately result from the existence of other knowledge and that is why they can be studied and assessed only in comparison to one another" (Santos 2010, 429). 
The second argument consists, in fact, in transferring the first one onto the plane of community. Alcoff associates ignorance with particular aspects of group identity. Group identities express themselves through a significant epistemic difference, yet this is determined neither by the identity itself, nor by the fact that groups employ various procedures to justify their claims. This is determined by the fact that they work on the basis of dissimilar initial sets of beliefs determined by social locations and experience, which in turn determine their epistemic operations - the assessment of coherence and reliability of knowledge. The fact of universal location does not, however, entitle us to ignorance. It should rather make us aware that a given epistemic situation can be favourable or unfavourable, depending on the epistemic goal. In this context, Alcoff speaks about the need to develop what Sandra Harding called "the geography of epistemic terrain," aimed at an analysis of epistemic location of the knowing subject and vast implications related to it (Alcoff 2007, $43-47$ ). The epistemic difference appears then in relationships between various kinds of knowledge within the same culture, as well as in relationships between different cultures. Santos believes that at the latter level there is a complex asymmetry, since despite its epistemological character, it is more of a political issue. In other words, the asymmetry of knowledge is imposed on the asymmetry of power. It can be induced in two ways. The first one consists in maximizing ignorance of another knowledge, that is propagating its nonexistence, destroying or suppressing it on purpose. Santos calls these activities "an epistemological fascism" - a form of "murder of knowledge", "epistemicide", whose most violent version consisted in silencing non-Western knowledge by European colonialists. This form is typical of hegemonic epistemologies of the Western modernity. The other way is visible in trying to minimize epistemological differences by mutual comparisons and dialogue between particular kinds of knowledge in search for the opportunity to go beyond their boundaries. Santos sees an opportunity to implement this postulate in the concept of ecology of knowledge he created, based on the belief in the contextual nature of knowledge and its close relationship with practice. Social relationships are always cultural and political; thus, every knowledge is born as a result of particular contexts. Ignoring them, purposefully eliminating the conditions of producing and reproducing knowledge from cultural and political reflection, according to Santos, constitutes a cardinal error of the epistemology of the last two centuries, which has led to perpetuating inequalities and ignorance (Santos 2010, 13, 430; Santos 2014, 22).

Following Charles Mills, in her third argument, Alcoff points at the need to undertake structural explorations of ways in which oppressive systems generate ignorance as one of the effects of their actions. The structural argument focuses on specific epistemic practices implemented in dominant social groups. In every system there are 
dominant views on the general character of society ${ }^{2}$ which reveal specific forms of inequality and abuse, yet are presented as essentially just and fair. The persistence of social myths sanctioning unjust or immoral actions of privileged groups indicates that epistemic dysfunctions responsible for maintaining them come down to something more than just dissimilar experience or differences in specialized knowledge (Alcoff 2007, 47 - 50). Cultural and political relationships do not exist in a vacuum, they are deeply rooted in structures of knowledge. If the fight against injustice is to be effective, this correlation cannot be overlooked or ignored.

\section{Social significance of epistemic ignorance}

In the epistemic understanding of the word, ignorance is perceived as a gap in knowledge, an epistemic understatement whose identification implies its elimination. Meanwhile, in practice, it becomes more than just an accidental by-product of our lack of knowledge. It often assumes the form of various kinds of oppression, open repressions (most often racial) or simply ignoring injustice or cruelty. All oppressive practices prove to be closely related to our concepts and products of knowledge (Sullivan, Tuana 2007, 2). This is the meaning in which epistemological ignorance emerges as an important epistemic practice in its own right. In such a form, it is instrumental in building structures in which we function. Even if they are based on faulty assumptions, only images, they are significant for the way in which we perceive, order and act in reality. Thus, epistemic ignorance - like any other of its forms - is based upon a significant constitutive assumption which, as it appears, does not have to necessarily find its confirmation in reality. Ignorance is born as based on differences we create, antagonisms generated within the field of what Edward Said called "imaginative geography," i.e.:

The universal practice of designating in one's mind a familiar space which is "ours" and an unfamiliar space beyond "ours" which is "theirs" is a way of making geographical distinctions that can be entirely arbitrary. I use the word "arbitrary" here because imaginative geography of the "our land-barbarian land" variety does not require that the barbarians acknowledge the distinction. It is enough for "us" to set up these boundaries in our own minds (Said 1978, 54).

Systematic ignorance is born out of that sort of images, freely connected to the reality, on the basis of which the myth structure is built. Thus, the relation between

2 That refers not only to views on the general character of society but also on the general character of the natural world. 
imagination, ignorance, and myth is, in a way, of a cause-and-effect nature: imagination is fodder for ignorance and when combined, in turn, they are a strong driving force for mythical thinking. They become tools to map social reality, to order and to make the multi-aspect nature of the human world more understandable, as it may seem. It effects, however, in mythologizing social reality, which confirms Cassirer's thesis on our irrational attitude towards it. We simplify what is complicated, we get rid of doubts, we impose an apparent clarity on the world - and we satisfy our need for sense, order, and significance by that. By situating events in our narrative, we provide meanings to them and spur into specific actions. It is my means of myths, especially political ones, that we reach our goals, stage our history, manipulate the public (Błahut-Prusik 2019).

Hence, systematic ignorance keeps growing on socially constructed antagonisms, for which certain beliefs seem to be pivotal - as for instance the one on the existence of a clearly defined difference between "us" and "them" (Said 2009, XXXi). The differentiation into "us" and "them" unavoidably leads to some form of domination or attempts to establish it, which is why, although imagined, it never remains indifferent or neutral towards our actions. The practice of mentally marking some space as "ours" and some other space, outside ours, as "theirs" constitutes a significant point of reference of racist and imperial ideologies as well as colonial practices. This is a tool of mythologizing social reality, putting it in order, assigning meaning to some of its elements and subjects which create it, and in consequence - depriving others of this meaning. Boundaries outlined in the minds where "the untamed space outside of our borders is populated by all sorts of arbitrary assumptions, associations and fictions" (Said 2009, XXIV) become no less real than geographical borders. What is engendered as a result of this type of mythical knowledge is, among others, ignorance in relation to which we organize, put in order and evaluate reality. Myths, as emphasized by Chiara Bottici, rather than describing reality, project it. "They do not aim to 'describe' it, but rather, so to speak, to 'create' their own world. To paraphrase Wittgenstein, they are self-fulfilling” (Bottici 2011, 34). The imaginative character of myths causes that "truth and falsity are not the criteria according to which they should be judged" (Bottici 2011, 39), which locates them outside the area of classical epistemology. However, the fact of removing them from the criterion of truth and falsity does not eliminate the practical results myths carry, this does not render reflection on myths redundant. On the contrary, real consequences of myths make this reflection necessary, locating them within the research field of social epistemology, including the epistemology of ignorance. 


\section{"White" vs "black"}

One of the self-fulfilling myths based on the juxtaposition of "us" and "them" is the social ontology of "white," which has created its Other with the help of a conducive narrative, at the same time placing itself in a privileged position. As pointed out by George Yancy, "white" expresses itself through an imperial, hegemonic perspective through which it sees only what it wants to see, thus it identifies what is sees with what is. Its strength, power and privileges originate from the conviction that there is objective reality, yet one that it creates. "White" has given itself the power to create an imagined social deception leading, both whites and non-whites, to the belief that representations in categories in which whites live and understand the world and themselves are naturally given, universal ways of life. As a result, in the social encounter with "black," "white" - within its social-ontological cartography - has become the centre of economic and political power; it is believed to be superior intellectually, culturally, aesthetically and religiously. "Black", in turn, is seen only through the prism of the (superior) "white," as a body imprinted in the cultural and historical meanings originating in the power of "white". It is nothing more and nothing less than an extension of what "white" is. What is more, in its pure form "black" is a denial of "white". "The black body is by nature criminal, because the white body is by nature innocent, pure, and good. Whiteness sets itself up as the thesis. Blackness, within the dialectical logic of whiteness, must be the antithesis" - concludes Yancy $(2004,26)$. Although the white ontology is rooted in the empirically empty notion of "race", it does not devoid it of its social meaning and consequences. In the social space, "white" is not unreal. On the contrary, it embodies the difference which really influences the way of thinking and acting both in whites as well as non-whites. It is a way of life and its understanding based on the functional hegemonic axiological system, which strictly determines the relationship between "white" and "black". This relationship, which cannot be changed, as the social ontology of "white" determines the space entirely, is totalizing, terrorist, brutalizing, denying (Yancy 2004, 26, 29, 31 - 32, 34 35) - ignoring!

Mills suggests that both the notion of racial difference and its socio-political consequences make it impossible to truly perceive non-whites, and they constitute a barrier than is difficult to cross in their moral, fair treatment. Moreover, abandoning the primary meaning of racial difference did not put an end to white normativity, only subtly changed its character. Earlier, "white" was marked as biologically and culturally superior, now white normativity transpires mainly in refusal to acknowledge the long history of structural discrimination which granted whites various resources and all the ensuing benefits in negotiating possible structures (Mills 2007, 27 - 28). Mills interprets racial oppression in the categories of a reversed epistemology, the epistemology 
of ignorance, i.e. a special pattern of localised global epistemic dysfunctions, psychologically and socially functional, resulting in an ironic conclusion that whites, submerged in epistemic ignorance, are generally not capable of understanding the world which they created. Mills believes epistemology of ignorance to be part of the white state of supremacy, in which the human race is divided into humans and sub-humans, superior and inferior groups. Paradoxically, as whites usually do not understand the racist world in which they live, they can fully benefit from racial, ontological and economic hierarchies they have established (quoted in Sullivan, Tuana 2007, 2). Similar views are expressed by Alison Bailey, who considers white ignorance to be a form of lack of knowledge (flawed, misleading cognition) resulting from a habit of erasing, removing, distorting and forgetting the life, culture, and history of colonized peoples (Bailey 2007, 85). In turn, Santos claims that not seeing the permanence of the line separating metropolises from colonial societies is the most fundamental problem which we face today and which is the main symptom of ignorance. This is probably the most enduring and perhaps indelible echo of colonialism.

The twisted optics of "white normativity" as the central European, and then EuroAmerican point of reference, a constitutive norm strengthened in line with the gradual increase of European dominance in the world gave origin to the belief (still present, although in modified and subtler forms) that "white" is unique and superior, in line with the principle: "we rule the world because we are better, we are better because we rule the world". In the face of "white" as a full expression of humanity, the Other, non-white is marked with a number of historically rooted notions, whose common denominator is the subject located at a lower ontological and moral rank. For instance, the term "savage" - as shown by Francis Jennings - does not refer to knowledge, it was created for the sake of conquest, justifying the imperial practices. "Savagery" and "civilization" constituted a mutually inextricably conditioning whole which functions independently of the lack of necessary connections with empirical reality. European settlers did not exist earlier as with slave owners, just as the Yoruba did not exist as slaves (Mills 2007, $25-26$ ).

Mills suggests that white people become white as a result of a contract. He employs the term of "social contract" in order to show white supremacy as a global political system. The social contract of the Western theory is not made between everybody, only between those who matter, i.e. whites. For this reason, Mills calls this contract a "racial contract," 3 understood as a conceptual bridge between the main

\footnotetext{
${ }^{3}$ By constructing his "racial contract" Mills refers to Carole Pateman's "sexual contract". In Pateman's opinion the social contract that is presented as a story of freedom says that individuals form a civil society; however, it does not say anything about the fact that individuals, as discussed by John Locke, are men only. It means that "the original contract constitutes both freedom and
} 
(idealized) philosophical definitions of law, justice, good society - on the one hand, and African Americans, natives, imperial politics, colonialism, globalization - on the other. The racial contract has not only political, moral, but also epistemological consequences - it implicitly assumes an epistemological contract. The political division of society into "white citizens" and "black", "native", "coloured" sub-humans has its epistemological foundation. According to Mills, the racial contract implies a colour-coded epistemological, moral, legal white domination and the ensuing prejudice and ignorance. The racial contract is partly the result of a tacit consensus when it comes to epistemic norms, which state what counts as a correct interpretation of reality and what actions in connection with it are considered right, legal. It is a tacit consent to the misinterpretation of reality, serving to filter out empirical evidence that could undermine it and demythologize the fundamental beliefs upheld by a network of distortions and errors - building knowledge that generates inequality in an epistemically careless and irresponsible manner. As a result, this knowledge produces systemic epistemic impairment. The signatories of the contract are forced to adopt an officially sanctioned vision of reality, as only this allows them to become participants of white epistemic politics. Otherwise, they run the risk of suspicion, isolation, and accusations of madness. A sanctioned view of reality, despite the fact that it is imagined, brings with it real practical consequences (Bailey 2007, 79).

\section{Epistemic ignorance in the process of colonization}

The social significance of epistemic ignorance is confirmed by colonial practices, as signs of racism, for which the difference used against the "Other" in order to gain benefits by the discriminator proves to be rudimentary, can be found in the colonial heritage (Kubiaczyk 2014, 196 - 197). The influence of the North in the colonization process was so profound that it discredited all social practices of acquiring knowledge which opposed the imposed aim. The resulting implications were not limited to the epistemic area. As a result of this process, as pointed out by Santos, epistemological loss also entailed ontological harm - worse knowledge reduced its subject to the level of an inferior being. At the same time, the inferior ontological status as if granted the permission to ignore, marginalize and erase this subject. Ontological violence as a consequence of epistemic violence has been sanctioned by Eurocentric epistemology, which has found its expression both in science and in everyday life.

domination. Men's freedom and women's subjection are created through the original contract - and the character of civil freedom cannot be understood without the missing half of the story that reveals how men's patriarchal right over women is established through contract. Civil freedom is not universal" (Pateman 2003, 2). Pateman debunks the myth of all citizens' equality and freedom. 
The entire social (political, economic and cultural) superstructure regulating our actions in these areas is based on the Western epistemological paradigm. It also gave foundations to capitalism, colonialism and patriarchalism, which Santos recognizes as the most deeply socially rooted lies that rule our modern world, sustaining and justifying social injustice. As he points out:

It is a record of social regulation in the name of social emancipation, appropriation in the name of liberation, violence in the name of peace, the destruction of life in the name of the sanctity of life, violation of human rights in the name of human rights, societal fascism in the name of political democracy, illegal plundering in the name of the rule of law, assimilation in the name of diversity, individual vulnerability in the name of individual autonomy, constitution of subhumanities in the name of humanity, putting price tags on convictions in the name of priceless values, commodification in the name of redemption, standardization in the name of choice, massification in the name of freedom, racism in the name of tolerance, constitutional wrongs in the name of constitutional rights, ontologies of inferiority in the name of Immanuel Kant's Was ist die Aufklärung?, inequalities after the law in the name of equality before the law, compulsive consumption in the name of happiness, and hypocrisy in proclaiming principles (St. Thomas's habitus principiorum) in order to cover up for the most hideous negations of recta vita (Santos 2014, 10).

According to Santos, the epistemology of the North is responsible for, or even guilty of, creating and maintaining the ignorances which are extremely useful for it. Ignorances and the belief in cultural domination, as well as the universalism of values resulted in firmly established divisions Santos calls "lines of the abyss," separating metropolises from colonial societies, the centre from the periphery, us from Others, civilization from barbarism. As a result of "imaginative geographies," they are invisible and thus remain difficult and perhaps impossible to cross (Santos 2014, 26, 106). Santos, in the first place, attributes them with an epistemic character. On one side of the line there is science, philosophy and theology, on the other - those kinds of knowledge that do not fit into any of the Western ways of cognition and go beyond the categories of truth and falsity functioning in Western epistemology. These are: the common, secular, plebeian thought; beliefs, opinions, magic, idolatry, intuitive subjective understanding, basic knowledge. Anything arbitrarily assumed to be outside the rationalized area was ignored or stigmatized. The consequences of this epistemic dichotomy, however, go much further - they encompass a wide social sphere. Ultimately, they emerge in the permanent division of reality into "the universe on this side 
of the line" (Global North) - with universalistic and hegemonic patterns for establishing what is valuable and real, and "the universe on the other side of the line" (Global South)-invisible, insignificant and incomprehensible. Many centuries of repressions, exploitation, and the sense of imperial superiority gave birth to the abyss that absorbs everything on the other side, making it invisible, totally insignificant. The abyss metaphor is used by Santos to express his belief that Western thinking creates and validates knowledge similarly to the chasm separating theories developed in the North from those developed in the South. This distinction establishes a hierarchy expressed in the unilateral division of experiences and social actors into those who have a monopoly on certain and universal knowledge, which is why they are useful, understandable and visible, and those whose knowledge, reduced to opinions and viewpoints, makes them useless, incomprehensible, dangerous, consequently turning them into objects of silencing and marginalization. They are no alternative to the international regime of the North. Santos sees deliberate elimination of political and cultural contexts, conditions for the production and reproduction of knowledge, from epistemological reflection as a fundamental error in the epistemology of the North and the cause of perpetuating inequalities. The removal of the location of the knowledgegenerating subject facilitated making knowledge universal, and thus made it possible to create and impose a hierarchy of superior and inferior knowledge, better and worse people. Universalism is nourished by the ignorance of anything that is beyond the limits it outlines. The "epistemic murder of knowledge" implies "ontological murder" as a product of an unequal relationship between subjects of knowledge. The death of the subordinate subject's knowledge equals marginalization of social groups that create this knowledge (Santos 2010, 13, 25; Santos 2014, 22, 132 - 134, 167 - 170). A relationship in which they are perceived as different or alien is in fact the practice of removing their subjectivity, the practice of ignorance which is invisible due to epistemology, which - while looking for a way to find its universality - ignored its contextuality, fragmentation, incompleteness, relationality between the one who knows and what is known.

\section{Conclusions}

Presenting a relation between epistemic violence and epistemic ignorance seems to be crucial particularly in the situation of ongoing globalization. On the one hand, it has laid the results of colonialism bare; on the other, it has made subaltern classes speak their own voice. If the fight for global justice is to be effective, we cannot remain deaf to the voices opposing epistemic violence, ideologic poverty, or material results of neoliberal globalization. Nor can we remain blind to the existence of deeply-rooted divisions that not only are an echo of the colonial heritage but, most of all are a solid 
fundamental to build the Western identity. Fighting for global justice seems pivotal not only from the point of view of subaltern groups but also for survival of democratic norms and practices that are, according to the Western thought, constitutive for its identity and development.

There are many phenomena that can be analysed in relation to epistemic injustice as its source, manifestations, or implications. In the Western philosophical tradition, the issue of justice has been studied and scholars looked for tenets of knowledge and methods of obtaining it, rather than symptoms of lack of knowledge, i.e. ignorance. This goal has been pursued so persistently that we lost sight of and discredited other types of knowledge, while at the same time undermining the subjectivity of those who built their identity on it. These two areas were rarely considered together as conditioning one another. It turns out, however, that social injustice has its deep roots in the epistemic layer, which sanctions and justifies it, while making it invisible.

The voice of neo-colonial societies - although articulated more and more often - remains profoundly marked by the colonial power and the resultant ignorance. The former colonized to this day has remained a passive recipient of Western patterns, and the global international regime of the North still seems to have no real alternative. We live in a postcolonial era, even if political and economic colonial practices are not performed, they are still present in the consciousness, in social perceptions and in structures of knowledge. The epistemic ignorance is an everyday strategic practice of maintaining the centuries-long relationships of power, a practice which is so deeply rooted that it is considered obvious. As Anibal Quijano and Michael Ennis indicate:

The Eurocentric version is based on two principal founding myths: first, the idea of the history of human civilization as a trajectory that departed from a state of nature and culminated in Europe; second, a view of the differences between Europe and non-Europe as natural (racial) differences and not consequences of a history of power. Both myths can be unequivocally recognized in the foundations of evolutionism and dualism, two of the nuclear elements of Eurocentrism (Quijano, Ennis 2000, 542).

In the North, as Mills emphasizes, relationships of power grew on the tacit assumption that only Europeans were human. It resulted in the "naturalization" of countless socio-epistemic patterns and practices of inequality and oppression, permeating the entire fabric of society. Mills recognizes The History of British India by James Mill as a symbol of the politics of unconsciousness, a symbol of how effectively the $19^{\text {th }}$-century British colonial theory and practice were shaped, a symbol of consent to tolerating ignorance aimed at colonized people, places and the environment in the name of deceptive, often compulsory, paternalistic assumptions about universal 
human nature, universal needs, practices, values, customs, which are reinforced by the image of colonies as terra nullius (quoted after: Code 2007, $214-215,218$ ). The "epistemic murder of knowledge" leads not only to the removal of another subjectivity, but also to "stealing" their history. The Other, deprived of their own history and subjectivity, becomes an object of silencing, marginalizing and stigmatizing ignorance.

Extending the field of studies of traditional epistemology to include social epistemology and the epistemology of ignorance emerging therein allows one to see the far-reaching consequences of the Western epistemological paradigm, gives one an opportunity to have a more comprehensive insight into the divisions which are perpetuated in practice and consciousness, as well as into social problems rooted in them. The question of the epistemology of ignorance appears to be an interesting one in that context. Could the epistemology of ignorance be "added" to traditional epistemology? Or does thematizing the issues of epistemic ignorance and injustice need to reconceptualize the very principia of the traditional theory of knowledge? The issue, however, requires an additional deeper reflection.

\section{Bibliography}

ALCOFF, L. M. (2007): Epistemologies of Ignorance. Three Types. In: Sullivan, S. - Tuana, N. (eds): Race and Epistemologies of Ignorance. New York: State University of New York Press, $39-57$.

BAILEY, A. (2007): Strategic Ignorance. In: Sullivan, S. - Tuana, N. (eds): Race and Epistemologies of Ignorance. New York: State University of New York Press, 77 - 94.

BERRETO, J-M. (2014): Epistemologies of the South and Human Rights: Santos and the Quest for Global and Cognitive Justice. Indiana Journal of Global Legal Studies, 21 (2), 395 - 422.

BŁAHUT-PRUSIK, J. (2019): "Inny" jako wytwór imaginacyjnej geografii a globalizacja. Studia Europaea Gnesnensia, 19, 183 - 195.

BOTTICI, C. (2011): Towards a Philosophy of Political Myth. European Journal of Philosophy and Public Debate, III 5 April, 31 - 52.

CODE, L. (2007): The Power of Ignorance. In: Sullivan, S. - Tuana, N. (eds): Race and Epistemologies of Ignorance. New York: State University of New York Press, $213-230$.

DOTSON, K. (2011): Tracking Epistemic Violence, Tracking Practices of Silencing. Hypatia, 26 (2), $237-257$.

GALVÁN-ÁLVAREZ, E. (2010): Epistemic Violence and Retaliation: The Issue of Knowledge in Mother India. Atlantis. Journal of the Spanish Association of Anglo-American Studies, 32 (2), $11-26$.

KUBIACZYK, F. (2014): Otwarta rana (post)kolonialna, Studia Europaea Gnesnensia, 10, 195 230.

MILLS, Ch.W. (2007): White Ignorance. In: Sullivan, S. - Tuana, N. (eds): Race and Epistemologies of Ignorance. New York: State University of New York Press, 13 - 38.

PATEMAN, C. (2003): The Sexual Contract. Cambridge: Polity Press.

POHLHAUS, G. (2017): Varieties of Epistemic Injustice. In: Kidd, I. J. - Medina, J. - Pohlhaus, G. Jr. (eds.): The Routledge Handbook of Epistemic Injustice. New York: Routledge \& CRC Press, $43-71$. 
FRICKER, M. (2007): Epistemic Injustice. Power and the Ethics of Knowing. New York: Oxford University Press.

QUIJANO, A., ENNIS, M. (2000): Coloniality of Power, Eurocentrism, and Latin America. Neplanta: Views from South, 1 (3), 533 - 580.

SAID, E. (1978): Orientalism. New York: Pantheon.

SAID, E. (2014): Culture and Imperialism. London: Vintage Books.

SANTOS, B. (2010): Para alem do pensamento abissal: das linhas globais a uma ecologia de saberes. In: Santos, B. - Paula, M. M. (eds.): Epistemologias do Sul, ed. São. Paulo: Cortez Editora.

SANTOS, B. (2014): Epistemologies of the South: Justice Aagainst Epistemicide. London: Routledge \& CRC Press.

SPIVAK, G. (1998): Can the subaltern speak? In: Nelson, C. - Grossberg, L.: Marxism and the interpretation of culture. Urbana: University of Illinois Press.

SULLIVAN, S., TUANA, N. (2007): Introduction. In: Sullivan, S. - Tuana, N. (eds): Race and Epistemologies of Ignorance. New York: State University of New York Press, 153 - 172.

YANCY, G. (2004): Introduction. Fragments of a Social Ontology of Whiteness. In: Yancy, G. (ed.): What White Looks Like, African-American Philosophers on the Whiteness Question. New York: Routledge \& CRC Press.

Jadwiga Błahut-Prusik

University of Warmia and Mazury in Olsztyn

Instytut Filozofii UWM w Olsztynie

ul. Kurta Obitza 1

10-725 Olsztyn

Poland

e-mail: jadwiga.blahut@uwm.edu.pl

ORCID: https://orcid.org/0000-0003-0741-468X 